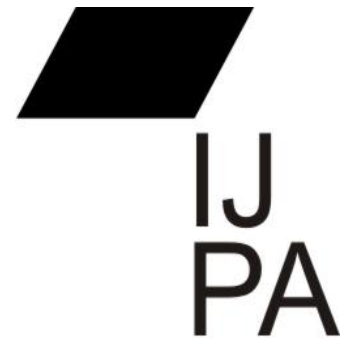

ISSN $2460-0369$

\section{IMPLEMENTASI STRATEGI PADA PENGEMBANGAN WISATA DIENG KABUPATEN BANJARNEGARA}

\section{NURLAILI RESTIANA, DENOK KURNIASIH, MUSLIH FAOZANUDIN}

\author{
Program Pascasarjana Ilmu Administrasi \\ Universitas Jenderal Soedirman \\ lelyrestiana@gmail.com
}

\begin{abstract}
The development of the tourism sector is very important, especially for the District of Banjarnegara in the area of Tourism Dieng which is a natural tourist area that attracted many visitors. Tourism sector is the main sector of the economy of Banjarnegara Regency, but tourism development of Banjarnegara Regency also raises obstacles, so that tourism development effort needs to be done with and appropriate strategy. The research method used is qualitative method, with technique of selecting informant purposive sampling. From the result of the research, it is known that Implementation of development strategy of Dieng tourism area in Banjarnegara regency generally has been running well enough seen from 3 (three) aspects ie program, resources, and procedure. Researchers found that the development program of tourism destinations and technological resources capable of supporting the development of tourism Dieng. But there are still shortcomings in the aspect of resources, namely financial resources are still limited from the budget and there are still inadequate physical resources.
\end{abstract}

Keywords: Strategy Implementation, Tourism Development, Nature Tourism

\begin{abstract}
Abstrak: Pembangunan sektor pariwisata sangat penting, khususnya untuk Kabupaten Banjarnegara pada kawasan Wisata Dieng yang merupakan kawasan wisata alam yang cukup diminati banyak pengunjung. Sektor pariwisata menjadi sektor unggulan perkonomian Kabupaten Banjarnegara, namun pembangunan pariwisata Kabupaten Banjarnegara juga memunculkan kendala, sehingga upaya pengembangan pariwisata perlu dilakukan dengan dan strategi yang tepat. Metode penelitian yang digunakan adalah metode kualitatif, dengan teknik pemilihan informan purposive sampling. Dari hasil penelitian diketahui bahwa Implementasi strategi pengembangan kawasan wisata Dieng di Kabupaten Banjarnegara secara umum sudah berjalan dengan cukup baik dilihat dari 3 (tiga) aspek yaitu program, sumber daya, dan prosedur. Peneliti menemukan bahwa program pengembangan destinasi pariwisata dan sumber daya tekhnologi mampu mendukung pengembangan wisata Dieng. Namun masih ada kekurangan dalam aspek sumber daya yaitu sumber daya keuangan masih terbatas dari APBD dan masih ada sumber daya fisik yang belum memadai.
\end{abstract}

Kata kunci: Implementasi Strategi, Pengembangan Pariwisata, Wisata Alam 


\section{PENDAHULUAN}

Pembangunan kepariwisataan mempunyai peranan penting dalam meningkatkan penyerapan tenaga kerja, mendorong pemerataan kesempatan berusaha, mendorong pemerataan pembangunan nasional dan memberikan kontribusi dalam penerimaan devisa negara yang dihasilkan dari kunjungan wisatawan mancanegara, serta berperan dalam mengentaskan kemiskinan yang pada akhirnya akan meningkatkan kesejahteraan rakyat.

Seiring dengan hal tersebut, kawasan wisata Dieng Kabupten Banjarnegara merupakan salah satu daerah yang memiliki potensi kekayaan alam yang terus dikembangkan sebagai tujuan wisata bagi wisatawan nusantara maupun wisatawan mancanegara. Sektor Pariwisata di Banjarnegara merupakan sektor yang dapat menyumbang Pendapatan Asli Daerah (PAD), khususnya kawasan Wisata Dieng, dimana PAD wisata Dieng dari tahun 2011 sampai tahun 2016 secara nominal mengalami kenaikan. Berikut ini disajikan tabel kontribusi sektor Wisata Dieng terhadap PAD:

Tabel 1.1 Kontribusi sektor Wisata Dieng terhadap Pendapatan Asli Daerah (PAD) tahun 2011-2016 (dalam Rupiah)

\begin{tabular}{ccc}
\hline No. & Tahun & Jumlah \\
\hline 1 & 2011 & 969.473 .000 \\
2 & 2012 & 1.687 .330 .500 \\
3 & 2013 & 1.741 .745 .000 \\
4 & 2014 & 2.969 .685 .000 \\
5 & 2015 & 3.458 .510 .000 \\
6 & 2016 & 4.391 .650 .000 \\
\hline \multicolumn{2}{l}{ Sumber: Data Dinas Pariwisata Banjarnegara }
\end{tabular}

Selain itu, pengunjung Wisata Dieng juga mengalami kenaikan setiap tahunnya, yaitu dari tahun 2011 sampai tahun 2016. Berikut disajikan tabel jumlah kunjungan wisata Dieng:

Tabel 1.2 Jumlah kunjungan wisata Dieng

\begin{tabular}{cccrc}
\hline No & Tahun & $\begin{array}{c}\text { Jumlah } \\
\text { wisnus }\end{array}$ & $\begin{array}{c}\text { Jumlah } \\
\text { wisman }\end{array}$ & $\begin{array}{c}\text { Total } \\
\text { pengunjung }\end{array}$ \\
\hline 1 & 2011 & 104.911 & 5.175 & 110.086 \\
2 & 2012 & 159.048 & 7.373 & 166.421 \\
3 & 2013 & 176.659 & 7.433 & 184.092 \\
4 & 2014 & 290.290 & 7.360 & 297.650 \\
5 & 2015 & 340.892 & 7.875 & 348.767 \\
6 & 2016 & 385.665 & 5.804 & 391.469 \\
\hline \multicolumn{5}{l}{ Sumber: Data Dinas Pariwisata Banjarnegara }
\end{tabular}

\footnotetext{
Sumber: Data Dinas Pariwisata Banjarnegara
} 
Jumlah pengunjung Dieng tiap tahun meningkat, namun untuk jumlah pengunjung sumur Jalatunda turun secara signifikan dari jumlah 11.660 pada tahun 2015 menjadi 9.560 pada tahun 2016. Selain itu wisatawan nusantara pada kawah Sikidang juga turun yaitu dari jumlah 146.650 pada tahun 2015 menjadi 138.794 pada tahun 2016. Hal yang sama terjadi pada kunjungan daya tarik wisata telaga Merdada, kawah Candradimuka dan kawah Sileri dengan jumlah pengunjung mengalami penurunan pada tahun 2015 sampai tahun 2016.

Strategi yang diterapkan Dinas Pariwisata dan Kebudayaan Banjarnegara dalam pengembangan Wisata Dieng yang tercantum dalam Rencana Induk Pembangunan Kepariwisataan Daerah Kabupaten Banjarnegara Tahun 2015-2030 adalah strategi mengembangkan kawasan Wisata Dieng.

Untuk mendukung implementasi strategi pada kawasan Wisata Dieng, sudah seharusnya semua pihak terlibat yaitu seperti bidang destinasi pariwisata, bidang pemasaran pariwisata, bidang kelembagaan dan sumber daya manusia pariwisata, bidang kebudayaan, UPTD Dieng serta stakeholder yang lain untuk bekerjasama dalam mengembangkan program, memberdayakan sumber daya dan prosedur. Tujuan program dibuat adalah untuk membuat strategi dapat dilaksanakan dalam tindakan (action-oriented). Setelah semua program yang dibutuhkan disusun, langkah selanjutnya adalah memberdayakan sumber daya untuk mendukung program, dan langkah terakhir adalah mengembangkan prosedur. Prosedur berisi rincian berbagai aktivitas yang diperlukan dalam menyelesaikan sebuah program.

Pembangunan sektor pariwisata sangat penting, khususnya untuk Kabupaten Banjarnegara pada kawasan Wisata Dieng yang merupakan kawasan wisata alam yang cukup diminati banyak pengunjung. Namun ada beberapa permasalahan yang muncul dalam pengelolaan Wisata Dieng. Oleh karena itu, peneliti tertarik untuk meneliti tentang "Implementasi Strategi Pengembagan Wisata Dieng Kabupaten Banjarnegara” 


\section{TINJAUAN PUSTAKA}

\section{Konsep Implementasi Strategi}

1) Implementasi strategi

Implementasi strategi adalah proses dimana manajemen mewujudkan strategi dan kebijakannya dalam tindakan melalui pengembangan program, anggaran dan prosedur. Proses tersebut meliputi perubahan budaya secara menyeluruh, struktur dan atau sistem manajemen dari organisai secara keseluruhan (Hunger \& Wheelen, 2003: 17). Menurut Hunger \& Wheelen (2003:17-18) dalam pelaksanaan implementasi strategi, dengan cara mengembangkan program, anggaran, dan prosuder.

Menurut David (2009: 389) isu-isu utama bagi penerapan strategi meliputi penetapan tujuan tahunan, pembuatan kebijakan, alokasi sumber daya, perubahan struktur organisasi yang ada, restrukturisasi dan rekayasa ulang, perbaikan program penghargaan dan insentif, meminimalisi penolakan terhadap perubahan, pengenalan manajer pada strategi, pengembangan budaya yang mendukung strategi.

\section{Konsep Pariwisata}

Menurut Pendit (1999: 35) pariwisata adalah salah satu jenis industri baru yang mampu menghasilkan pertumbuhan ekonomi yang cepat dalam menyediakan lapangan pekerjaan, peningkatan penghasilan, standar hidup serta menstimulasi sektor-sektor produktivitas lain. Menurut Suwantoro (2004: 3) pariwisata adalah suatu proses perubahan tempat tinggal sementara seseorang di luar tempat tinggalnya karena suatu alasan dan bukan untuk melakukan kegiatan yang menghasilkan upah. Menurut Suwantoro (2004: 56) pengembangan pariwisata sering dikaitkan dengan adanya Sapta Kebijakan Pengembangan Pariwisata oleh Pemerintah. 


\section{METODE PENELITIAN}

Penelitian ini menggunakan metode penelitian kualitatif. Adapun fokus penelitiannya yaitu implementasi strategi pengembangan wisata Dieng Kabupuaten Banjarnegara yang dilihat dari 3 (tiga) aspek yaitu program, anggaran, dan prosedur.

Lokasi penelitian adalah di kawasan Wisata Dieng. Jenis data dalam penelitian adalah data primer dan data sekunder. Adapun sumber data diperoleh dengan cara observasi, wawancara, dan dokumentasi. Instrumen penelitian dalam pendekatan kualitatif ini meliputi peneliti sendiri, pedoman wawancara, pedoman dokumentasi, dan media atau perangkat penunjang.

Berdasarkan data yang berhasil ditemukan dan dikumpulkan di lapangan, selanjutnya peneliti melakukan analisis data dengan menggunakan model interaktif dari Miles, Huberman dan Saldana. Analisis data terdiri dari 4 (empat) alur kegiatan yaitu: pengumpulan data, kondensasi data, penyajian data, dan penarikan kesimpulan.

\section{PEMBAHASAN}

\section{Strategi Pengembangan Wisata Dieng}

Strategi pengembangan wisata Dieng yang dilaksanakan oleh Dinas Pariwisata dan Kebudayaan Kabupaten Banjarnegara mengacu pada Peraturan Daerah Kabupaten Banjarnegara Nomor 14 Tahun 2015 tentang Rencana Induk Pembangunan Kepariwisataan Daerah (RIPPDA) Kabupaten Banjarnegara Tahun 2015-2030. Strategi pengembangan kawasan wisata Dieng dijabarkan dalam program pengembangan destinasi pariwisata dengan 3 (tiga) kegiatan yang sudah terlaksana, antara lain yaitu kegiatan perbaikan akses jalan ke sumur Jalatunda, kegiatan penguatan kelompok seni budaya khas Dieng, dan kegiatan penambahan rambu pengaman di objek rentan bencana.

\section{Implementasi strategi pengembangan wisata Dieng Kabupaten}

\section{Banjarnegara}

Implementasi strategi pengembangan wisata Dieng Kabupaten Banjarnegara dilihat dari 3 (tiga) aspek yaitu program, sumber daya, dan 
prosedur. Program pengembangan destinasi merupakan program dalam pengimplementasian strategi pengembangan wisata Dieng. Dari program pengembangan destinasi pariwisata yang kemudian dirinci dalam berbagai kegiatan diantaranya yaitu kegiatan perbaikan akses jalan ke sumur Jalatunda, kegiatan penguatan kelompok seni budaya khas Dieng, dan kegiatan penambahan rambu pengaman di objek rentan bencana.

Program pengembangan destinasi pariwisata dengan tiga kegiatan yang telah terlaksana yaitu perbaikan akses jalan menuju sumur Jalatunda, penguatan kelompok seni budaya khas Dieng dan penambahan rambu pengaman di objek rentan bencana sudah sesuai dengan strategi pengembangan kawasan wisata Dieng dan sesuai dengan tujuan Dinas Pariwisata dan Kebudayaan Kabupaten Banjarnegara. Dengan perbaikan akses jalan ke Sumur Jalatunda, maka kondisi jalan menjadi lebih baik yaitu berupa aspal, kegiatan ini mendukung tujuan Dinas Pariwisata dalam rangka meningkatkan kualitas obyek di Kabupaten Banjarnegara dan mampu mengembangkan kawasan wisata Dieng. Jumlah kunjungan ke sumur Jalatunda juga meningkat dan hal tersebut sejalan dengan tujuan Dinas Pariwisata dalam meningkatkan minat wisatawan untuk berkunjung ke Banjarnegara. Berikut ini disajikan tabel kenaikan jumlah pengunjung:

Tabel 1.3 Data kenaikan jumlah pengunjung sumur Jalatunda

\begin{tabular}{ccc}
\hline No. & Periode & Jumlah pengunjung \\
\hline 1 & Januari - Desember 2016 & 9.560 \\
2 & Januari - Juni 2017 & 9.740 \\
\hline \multicolumn{2}{l}{ Sumber: Data UPTD Dieng }
\end{tabular}

Dari tabel 1.3 menunjukkan adanya kenaikan jumlah pengunjung sumur Jalatunda, pada tahun 2016 jumlah pengunjung sumur Jalatunda selama satu tahun sebanyak 9.560. Namun setelah akses jalan menuju sumur Jalatunda diperbaiki, berdasarkan laporan bulanan pengunjung dari UPTD Dieng selama 6 (enam) bulan yaitu bulan Januari sampai bulan Juni diketahui jumlah pengunjung sumur Jalatunda meningkat dan jumlah pengunjung sebanyak 9.740 . 
Penguatan kelompok seni budaya khas Dieng yang diwujudkan dengan fasilitasi oleh pihak Dinas Pariwisata Kabupaten Banjarnegara pada event Dieng Culture Festival (DCF) mampu mengembangkan kawasan wisata Dieng. Event DCF yang diselenggarakan oleh pokdarwis dan mendapatkan fasilitas dari pihak Dinas Pariwisata merupakan bentuk jaringan kerjasama promosi wisata dengan stakeholder pariwisata, dimana dalam event DCF mampu membantu promosi wisata Dieng kepada masyarakat nusantara bahkan mancanegara, mampu menyebarluaskan informasi potensi pariwisata Kabupaten Banjarnegara dan meningkatkan minat wisatawan untuk berkunjung ke Banjarnegara. Berikut disajikan perbandingan jumlah pengunjung pada bulan Januari - Juni 2016 dan bulan Januari - Juni 2017:

Tabel 1.4 perbandingan jumlah pengunjung Dieng pada bulan Januari Juni 2016 dan bulan Januari - Juni 2017

\begin{tabular}{cll}
\hline No. & Periode & Total kunjungan \\
\hline 1 & Januari - Juni 2016 & 231.516 \\
2 & Januari - Juni 2017 & 249.463 \\
\hline \multicolumn{2}{l}{ Sumber: Data UPTD Dieng }
\end{tabular}

Dari tabel 1.4 di atas menunjukkan kenaikan jumlah pengunjung pada perbandingan bulan Januari-Juni 2016 dengan bulan Januari-Juni 2017 dan hal ini membuktikan adanya minat wisatawan yang berkunjung ke kawasan wisata Dieng meningkat.

Penambahan rambu pengaman di objek rentan bencana sudah terealisasi karena lekat dengan keselamatan pengunjung, sehingga meningkatkan kualitas objek wisata di Banjarnegara. Dari program dan kegiatan yang terlaksana sudah sesuai dengan strategi pengembangan kawasan wisata Dieng dan sesuai dengan tujuan Dinas Pariwisata dan Kebudayaan Kabupaten Banjarnegara.

Berdasarkan deskripsi mengenai program pengembangan destinasi pariwisata di Dieng, tampak bahwa salah satu media untuk mengenalkan wisata dan meningkatan promosi wisata yaitu dapat dilaksanakan dengan cara "mengembangkan budaya setempat". Dapat dilihat pada event DCF yang dilaksanakan oleh pihak pokdawis, pihak pihak Dinas Pariwisata dan 
Kebudayaan Kabupaten Banjarnegara hanya memfasilitasi saja, sebagai bentuk penguatan kelompok seni budaya khas Dieng. Peran stakeholder pariwisata yaitu Pokdarwis sangat berpengaruh terhadap terlaksananya event DCF, sebagai pemikir dalam pengembangan budaya di Dieng. Dengan pelaksanaan event DCF mampu mengenalkan wisata Dieng kepada seluruh masyarakat nusantara dan mancanegara.

Sumber daya yang dimiliki Dinas Pariwisata dan Kebudayaan Kabupaten Banjarnegara dalam mendukung implementasi strategi pengembangan kawasan wisata Dieng melliputi sumber daya keuangan, sumber daya fisik, sumber daya manusia, dan sumber daya tekhnologi. Sumber daya tekhnologi sudah optimal dalam mendukung impelementasi strategi pengembangan wisata Dieng, yaitu dengan tersedianya web, facebook, instagram, email yang dapat mempermudah akses informasi bagi para pengunjung. Sedangkan sumber daya keuangan dan sumber daya fisik belum optimal dalam mendukung implementasi strategi pengembangan kawasan wisata Dieng. Sumber daya keuangan hanya bersumber dari APBD, sehingga kegiatan penambahan rambu pengaman di objek rentan bencana masih terbatas dan belum bersifat permanen. Sumber daya fisik masih ada yang belum memadai seperti akses jalan menuju kawah Candradimuka, toilet dan mushola juga ada yang belum memadai. Berdasarkan ABK sumber daya manusia masih kurang secara kuantitas dan secara kualitas belum mumpuni, namun berdasarkan dokumen LAKIP yaitu nilai pencapaian kinerja baik dengan dasar target tercapai lebih dari $95 \%$ dan hal ini dapat dilihat pada LAKIP Bab 4 halaman 46.

Prosedur dalam pengimplementasian strategi pengembangan wisata Dieng meliputi SOP dan prosedur pelibatan stakeholder. SOP yang ada belum memenuhi SOP yang ideal (berpedoman pada buku LAN, 2005:8), namun demikian apa yang disebut sebagai SOP oleh Pihak Dinpar Banjarnengara mampu memudahkan langkah petugas dan pengunjung. Stakeholder pariwisata Dieng meliputi BPCB, biro perjalanan dan pokdarwis. Prosedur pelibatan dengan BPCB melalui MOU, sedangkan pelibatan dengan biro perjalanan dan pokdarwis melalui pembinaan dan kerjasama. Dengan adanya SOP dan 
pelibatan stakeholder Pariwisata Dieng maka mampu mendukung implementasi strategi pengembangan wisata Dieng.

\section{PENUTUP}

\section{Kesimpulan}

Berdasarkan hasil penelitian dan pembahasan mengenai implementasi strategi pengembangan kawasan wisata Dieng di Kabupaten Banjarnegara secara umum sudah berjalan dengan cukup baik, yaitu:

1. Akses jalan merupakan faktor penting dalam pengembangan pariwisata, sehingga dengan perbaikan akses jalan menuju obyek wisata dapat meningkatkan jumlah kunjungan secara signifikan. Hal ini dapat dilihat dari hasil perbaikan akses jalan menuju sumur Jalatunda, kemudian mampu meningkatkan jumlah kunjungan pada obyek wisata Sumur Jalatunda.

2. Peningkatan promosi wisata dapat dilaksanakan dengan mengembangkan budaya setempat. Dapat dilihat pada event DCF yang dilaksanakan oleh pihak pokdawis, serta difasilitasi pihak Dinas Pariwisata dan Kebudayaan Kabupaten Banjarnegara sebagai bentuk penguatan kelompok seni budaya khas Dieng.

3. Peningkatan kualitas obyek wisata dapat dilakukan dengan adanya rambu pengaman, karena rambu pengaman lekat dengan keselamatan pengunjung.

4. Keterbatasan sumber daya manusia bukan menjadi alasan tidak terlaksananya suatu strategi. Dinas Pariwisata dan Kebudayaan Kabupaten Banjarnegara memiliki keterbatasan sumber daya manusia secara kuantitas maupun kualitas, namun berdasarkan dokumen LAKIP yaitu nilai pencapaian kinerja baik dengan dasar target tercapai lebih dari $95 \%$ dan hal ini dapat dilihat pada LAKIP Bab 4 halaman 46.

5. Sumber daya tekhnologi sangat berperan penting dalam promosi wisata. Dapat dilihat dengan pemanfaatan sumber daya tekhnologi secara optimal, maka dapat mengenalkan wisata Dieng kepada seluruh masyarakat nusantara maupun mancanegara. 
6. Pelibatan stakeholder pariwisata sangat berpengaruh terhadap pengembangan wisata. Dapat dilihat pada event DCF yang diselenggarakan oleh pokdarwis dan pihak Dinas hanya memfasilitasi serta memberikan pembinaan dan kerjasama (terdapat dalam dokumen LAKIP Bab 3 halaman 21). Event DCF mampu mengenalkan Dieng pada masyarakat nusantara dan mancanegara, serta mampu meningkatkan jumlah kunjungan.

Namun masih ada beberapa kekurangan diantaranya adalah sebagai berikut:

1. Sumber daya keuangan yang terbatas menyebabkan kurang optimalnya kegiatan yang terlaksana. Dapat dilihat dari penambahan rambu pengaman yang belum permanen. Sumber daya keuangan hanya bersumber dari APBD dan hal ini dibuktikan pada dokumen LAKIP Bab 3 halaman 48.

2. Sumber daya fisik sangat berpengaruh terhadap kualitas obyek wisata. Dapat dilihat dari kualitas akses jalan menuju Kawah Candradimuka yang kurang memadai, serta terdapat toilet dan mushola yang kurang memadai.

3. SOP merupakan upaya memberikan kepastian terhadap pelanggan, baik dari segi tahapan yang harus ditempuh oleh pelanggan, kepastian waktu dan kepastian biaya. Dapat dilihat dalam dokumen SOP UPTD Dieng baru memuat tata kerja yang harus dilaksanakan oleh petugas, sehingga SOP UPTD Dieng belum dapat dikatakan sebagai SOP yang ideal karena belum menjelaskan secara rinci mengenai siklus pelayanan.

\section{Saran}

Berdasarkan penelitian implementasi strategi pengembangan wisata Dieng di Kabupaten Banjarnegara, implikasi yang dapat diberikan dari penelitian ini adalah:

1. Perlu adanya penambahan sumber daya keuangan untuk pengimplementasian strategi pengembangan wisata Dieng. Pihak Dinas Pariwisata dan Kebudayaan Kabupaten Banjarnegara dapat memanfaatkan lokal wisdom yang ada Dieng untuk menambah sumber daya keuangan.

2. Perlu adanya pembenahan sumber daya fisik terutama pada akses jalan menuju kawah Candradimuka, toilet dan mushola agar kualitas obyek wisata 
Dieng lebih baik dengan harapan akan mampu meningkatkan jumlah kunjungan.

3. Dinas Pariwisata dan Kebudayaan Kabupaten Banjarnegara perlu menyusun kembali SOP yang ideal dan menjelaskan secara rinci mengenai siklus pelayanan yang ada di kawasan wisata Dieng

\section{DAFTAR PUSTAKA}

\section{Buku}

David, Fred R. 2009. Manajemen Strategis Konsep. Jakarta: Salemba Empat.

Hunger, J. David \& Wheelen, Thomas L. 2003. Manajemen Strategis. Yogyakarta: Andi Offset.

Keban, Yeremias T. 2004. Enam dimensi strategis Administrasi Publik. Yogyakarta: Gava Media.

Miles, M.B, Huberman, A.M, dan Saldana, J. 2014. Qualitative Data Analysis. USA: SAGE Publications, Inc.

Pendit, Nyoman Suwandi. 1999. Ilmu Pariwisata: Sebuah Pengantar Perdana. Jakarta: PT. Pradnya Paramita.

Sutarto. 2002. Dasar-dasar Organisasi. Yogyakarta: Universitas Gajah Mada Press.

Suwantoro, Gamal. 2004. Dasar-dasar Pariwisata. Yogyakarta: Andi.

LAN RI. 2005. Penyusunan SOP. Jakarta: LAN

\section{Jurnal}

Napitupulu, Wandi P. 2015. Implementasi Strategi Pengembangan Sektor Pariwisata Kabupaten Toba Samosir (Studi Pada Kantor Dinas Pariwisata dan KebudayaanKabupaten Toba Samosir). Medan: Skripsi Universitas Sumatera Utara.

Puri, Djanthi Kumala et al. 2014. Implementasi Strategi Perusahaan Daerah Air Minum dalam Peningkatan Pelayanan Pendistribusian Air (Studi pada Perusahaan Daerah Air Minum Kota Malang). Jurnal Administrasi Publik (JAP), Vol. 3, No. 12, Hal. 2133-2138.

Rajasekar, James. 2014. Factors affecting Effective Strategy Implementation in a Service Industry: A Study of Electricity Distribution Companies in the Sultanate of Oman. International Journal of Business and Social Science Vol. 5, No. 9(1), August 2014.

Rusdiananingtyas, Eva et al. 2014. Implementasi Strategi Pemerintah Daerah dalam Mewujudkan Pariwisata Berbasis Budaya Terkemuka (studi pada 
Dinas Pariwisata Provinsi Daerah Istimewa Yogyakarta). Jurnal Administrasi Publik (JAP), Vol. 3, No. 11, Hal. 1898-1904. 